ME becomes less of a house journal, then, but should still retain the loyalty of its author clientèle of earlier years. The first five issues show a predominance of central and southern European authors with interests in the Mediterranean. The standard of production is good; here and there an author has even been indulged in the luxury of a colour print. Strangely the journal lacks any detailed instructions for authors.

A completely new journal, Biological Oceanography, was launched in 1981 with Dr Richard Haedrich from Newfoundland

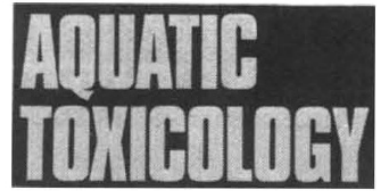

as the sole editor but supported, as with the other two journals under review, by a strong editorial board. There is no introductory editorial in Vol.1 No.1 but a search under "Information for Authors" shows that the journal aims

to advance understanding of the ocean as a biological system and publishes scientific papers and speculative notes from any branch of biology that contributes to this aim.

(It strikes me that the idea of speculative notes may restrict the authority of any refereeing system!)

The first three issues contain papers, mainly by North American authors, on conventional topics such as vertical migration, ichthyoplankton, marine phyto- and zooplankton and the design of samplers. However an intriguing title, "The distribution of linear rows of holes in the sea floor" is to be found in Vol.1 No.2 - tantalizingly, the maker of these holes was not identified.

A couple of general points may be made about these journals. Two of them require the return of proofs within two or three days of receipt. Surely it is unrealistic to expect scientists working on, say, research vessels to maintain such a strict schedule and, anyway, why should there be such an absurd rush after the author has waited several months for his or her paper to reach the proof stage? While none of the three journals levies page charges Biological Oceanography Vol.1 No.1 requests page charges "on a voluntary basis in exchange for additional free reprints" - a strange arrangement indeed (which becomes modified along more conventional lines in later issues).

Professor Rupert Reidl, in a long introductory article to Vol.1 of ME, describes four main phases in the history of marine science - the phase of seafarers, of oceanographic expeditions, of marine stations and of field research. We may add to this a fifth phase - the proliferation of published material.

J.H.S. Blaxter is Senior Principal Scientific Officer at the Dunstaffnage Marine Research Laboratory of the Scottish Marine Biological Association, Oban, Scotland.

\title{
Physics and physicians
}

\section{K.V. Ettinger}

Nuclear Medicine Communications. Editors K.E. Britton, P.J. Ell and R.F. Jewkes. 6/yr. (Chapman and Hall.) $£ 35$ UK, £39 elsewhere. Radiation Protection Dosimetry. Editor-in-chief T.F. Johns. $8 / \mathrm{yr}$ in 2 vols. (Nuclear Technology Publishing, PO Box 7, Ashford, Kent, UK.) $£ 60$ UK, $\$ 150$ elsewhere. Clinical Physics and Physiological Measurement. Honorary editors M.M. Black and P.H. Fentem. 4/yr. (Institute of Physics.) $£ 80$ UK, \$150 North America.

NUCLEAR medicine is one of the fastest growth areas of modern medicine, this fact being reflected in the multiple metastases of periodicals devoted to the field. The new arrival, Nuclear Medicine Communications (NMC), is a rapid-publication journal sponsored by the British Nuclear Medicine Society and having a particularly impressive editorial board.

The content reflects the traditional scope of nuclear medicine - use of radioisotopes

\section{Clinical Physics and Physiological Measurement}

in medical diagnosis and the management of disease and its follow-up; nuclear magnetic resonance imaging, however, which already claims a number of journals of its own, has still to make its impact felt on the pages of NMC. The journal accepts both clinically and experimentally orientated papers, as well as those concerned with the development of new instrumentation.

Editorials are lively and touch not only on problems of nuclear medicine but also on the intense competition in this and related fields, which appears to spill over from individuals to the scientific societies as a whole. The papers are short and most of the material is likely to appear later in an expanded (and often amended) form in another, non-rapid publication. Apart from the unsightly camera-ready format the standard of production is high. The journal is attracting moderately important contributions, and with its reasonable price it is a worthwhile publication vehicle for physicians, physicists, chemists, physiologists and others who are associated with nuclear medicine.

As journal titles get more specialized, the scope of the scientific field covered is accordingly narrowed. Furthermore, it is easier to search for one's favourite topics in a narrow-range periodical, particularly if computerized abstracting services are not at hand. Such a journal is Radiation Protection Dosimetry (RPD), which has reached a high level of scientific competence surprisingly quickly despite stiff competition from Health Physics, Journal of Applied Radiation and Isotopes, Radiation Physics and several others.

RPD is truly international in scope. Generally, it is addressed to the research community in the field of low-level radiation dosimetry and radiation protection, but some of the material published may be of interest to those involved in the less-loved regulatory side of radiation protection.

In addition to original scientific contributions covering the physical principles, instrumentation and practical implementation of low-level radiation dosimetry, there are well-written reviews of broad interest. Editorials are succinct and deal with scientific problems, not a common feature in specialized scientific periodicals. The subscription rate is high, but not exceptionally so.

Clinical Physics and Physiological Measurement (CPPM), the new sister journal to Physics in Medicine and Biology, is an official organ of the Hospital Physicists Association (UK), the German Society for Medical Physics and the European Federation of Organizations for Medical Physics. The aim of the editors is to present the latest work in aspects of medical physics, clinical engineering and physiological measurement. In practice the journal's coverage represents a continuation of the spectrum of its companion publication extended to the clinical and physiological side. The European contribution to the journal is hard to spot, but the editors do seem to be succeeding in attracting papers on the intended range of topics. The new European editor, C. Franconi, Rome, himself a rising star of continental medical physics, will undoubtedly improve the European coverage.

In such a broad and varied field it is difficult to judge the scientific quality of the articles, but from those published to date it appears that it is about the average. Good, readable reviews of books, lists of forthcoming events and announcements of professional societies also appear, and the standard of typography and binding is high.

For a long time there was a need for a publication to take the more clinically orientated papers originating from medical physicists, physiologists and biomedical engineers. CPPM is succeeding in this role and is virtually a must for every medical physics library. The price, however, is very steep. A question arises: if this journal and Physics in Medicine and Biology were merged into one, would it not be of benefit to both readers and the money conscious librarian?

K.V. Ettinger is Reader in Bio-Medical Physics and Bio-Engineering at the University of Aberdeen. 